\title{
Apolipoprotein status in type 2 diabetes mellitus and its complications (Review)
}

\author{
PUHONG ZHANG ${ }^{1,2}$, JIALIN GAO $^{3}, \mathrm{CHUN} \mathrm{PU}^{4}$ and YAO ZHANG ${ }^{1,5}$ \\ ${ }^{1}$ Anhui Province Key Laboratory of Biological Macromolecules Research, Wannan Medical College; \\ ${ }^{2}$ Department of Clinical Laboratory, The Second Affiliated Hospital of Wannan Medical College; Departments of \\ ${ }^{3}$ Endocrinology and Genetic Metabolism and ${ }^{4}$ Clinical Laboratory, Yijishan Hospital of Wannan Medical College; \\ ${ }^{5}$ Department of Biochemistry and Molecular Biology, Wannan Medical College, Wuhu, Anhui 241002, P.R. China
}

Received October 17, 2016; Accepted August 22, 2017

DOI:10.3892/mmr.2017.7831

\begin{abstract}
Dyslipidaemia in type 2 diabetes mellitus (T2DM) is characterized by high plasma triglyceride concentrations, reduced high-density lipoprotein concentrations and increased small density low-density lipoprotein concentrations. Dyslipidaemia may lead to cardiovascular disease (CVD) and other complications. Apolipoproteins mainly comprise six species, apolipoprotein (apo)A, apoB, apoC, apoD, apoE and apoM, which are important components of plasma lipoproteins that carry lipids and stabilize the structure of lipoproteins. Complex metabolic disorders of apolipoproteins are present in T2DM, such as high plasma apoB, apoC-II, apoC-III and apoE concentrations, and low plasma apoA-I and apoM concentrations, which are associated with dyslipidaemia and interrelated complications. Plasma concentrations of some apolipoproteins are also altered in T2DM with CVD or other complications. Several apolipoprotein polymorphisms are associated with diabetes susceptibility and/or lipid metabolism. The present review described the metabolic disorders of apolipoproteins in T2DM and its complications, and the relationship between each major apolipoprotein and T2DM, as well as the effects of apolipoprotein polymorphisms on diabetic susceptibility.
\end{abstract}

\section{Contents}

1. Introduction

2. Relationship between apoA and T2DM

3. Relationship between apoB and T2DM

Correspondence to: Professor Yao Zhang, Department of Biochemistry and Molecular Biology, Wannan Medical College, 22 West Wenchang Road, Wuhu, Anhui 241002, P.R. China

E-mail: zhangyao@ahedu.gov.cn

Key words: apolipoproteins, polymorphisms, high-density lipoprotein, type 2 diabetes mellitus, complications
4. Relationship between apoC and T2DM

5. Relationship between apoD and T2DM

6. Relationship between apoE and T2DM

7. Relationship between apoM and T2DM

8. Conclusions and prospects

\section{Introduction}

Patients with type 2 diabetes mellitus (T2DM) have an increased risk of cardiovascular disease (CVD), which remains the leading cause of morbidity and mortality worldwide (1). A major risk factor of CVD in T2DM is dyslipidaemia, which is characterised by reduced high-density lipoprotein (HDL), and increased triglyceride (TG) and small density low-density lipoprotein (sd-LDL; Fig. 1) (2). Apolipoproteins are the protein portion of lipoproteins, and mainly comprise six species called apolipoprotein (apo)A, apoB, apoC, apoD, apoE and apoM, some of which have several subtypes. Apolipoproteins are important components of plasma lipoproteins and are expressed mainly in the liver and partly in the intestine and other tissues (3). Their basic function is to carry lipids and to stabilise the structure of lipoproteins; some apolipoproteins also activate enzymes that participate in the metabolism of lipoproteins and recognise endothelial receptors associated with inflammatory signaling pathways (3). Previously reported epidemiological data suggested that the metabolic disorders of apolipoproteins are associated with the pathophysiological processes of T2DM (Fig. 1) $(3,4)$. The present review described the metabolic disorders of apolipoproteins in T2DM and the relationship between each major apolipoprotein and T2DM, associated complications and the effects of apolipoprotein polymorphisms on diabetic susceptibility.

\section{Relationship between apoA and T2DM}

Introduction to apoA. The human apoA family includes apoA-I, apoA-II, apoA-IV and apoA-V. ApoA-I is mainly distributed in the plasma chylomicrons (CMs), HDL2 and HDL3, and is the major component of HDL, comprising 70\% total protein content of HDL (5). Plasma HDL concentration 
is determined by the fractional catabolic rate of apoA-I and apoA-II, as well as HDL reduction with apoA-I deficiency. Therefore, apoA serves an important role in the metabolism of HDL (6). ApoA may enhance the hydrolysis of TGs with endothelial lipoprotein lipase (LPL) by stabilising the structure of LPL dimers or TG-rich lipoproteins; as such, apoA deficiency has been associated with atherosclerosis (6). ApoA-I serves an important role in glucose stabilisation and the function of mitochondria in muscle (7). Lipid-free and lipid-associated apoA-I and apoA-II concentrations increase $\beta$-cell insulin secretion and reduce the plasma level of glucose (8); thus, they may serve a protective role in T2DM. However, the fractional catabolic rate of apoA-I is significantly higher, and the absolute production rate of apoA-I is inhibited in patients with T2DM compared with healthy individuals; this inhibition may lead to a decrease in plasma apoA-I levels, which may contribute to low HDL (Fig. 1; Table I) (9). In addition, increased production of inflammatory cytokines, such as tumour necrosis factor $\alpha$, may increase insulin resistance and directly downregulate apoA-I expression in T2DM (Fig. 1) (10).

Metabolism of apoA in T2DM and its complications. T2DM leads to arteriosclerosis and reduces the antioxidant properties of human apoA-I, which inhibits hyperglycaemia-induced oxidative stress and the production of NADPH-mediated reactive oxygen species (ROS) in human macrophages (11). Nobécourt et al (3) concluded that the non-enzymatically glycated apoA-I was attributed to a reduced ability to inhibit nuclear factor $-\kappa \mathrm{B}$ activation and ROS formation. However, glycated apoA-I plasma concentration is usually increased in patients with T2DM, leading to a reduction in anti-inflammatory effects, which may enhance the inflammatory response (3). apoA-I levels are low when apoA-I glycation is significantly elevated in patients with T2DM and significant coronary artery disease (CAD). Therefore, the baseline relative intensity of apoA-I glycation is an independent determinant of CAD and plaque progression in T2DM (12). The plasma apoA-IV concentration was reported to be significantly lower in patients with T2DM, and low apoA-IV concentration was strongly associated with the risk of all-cause mortality and cardiac disease-related mortality, particularly sudden cardiac death (13). Compared with patients with mild non-proliferative diabetic retinopathy, those with proliferative diabetic retinopathy are characterised by decreased serum apoA-I levels and decreased apoA-I/apo-B ratio (14). Furthermore, the apoA-IV content may be significantly higher in morbidly obese persons (MOPs) with T2DM compared with MOPs without T2DM (15). Women with polycystic ovary syndrome were indicated to have an increased risk of developing T2DM; therefore, apoA-I may be used to identify high-risk subgroups (16). ApoA-I expression is lower in persons with combined metabolic syndrome (MetS) and T2DM compared with those with MetS alone, which suggested that diabetes may adversely influence plasma apoA-I levels (Table I) (17).

apoA gene mutations and polymorphisms in T2DM. Gene mutations and polymorphisms may affect plasma lipid levels and may lead to CVD and atherosclerosis (18). The apoA-V $1131 \mathrm{~T}>\mathrm{C}$ single-nucleotide polymorphism (SNP) has been associated with increased plasma TG in both healthy people and those with T2DM (19). The hypertriglyceridaemic effect of high retinol-binding protein (RBP)4 expression levels was demonstrated to be enhanced by the presence of the apoA-V $1131 \mathrm{~T}>\mathrm{C}$ genetic variant, indicating that this variant increases plasma TG by regulating RBP4 (20). However, previous studies that did not observe the aforementioned association concluded that a higher TG level in T2DM may be the result of insulin resistance and reduced lipolysis rather than genetic polymorphisms in apoA-V 1131T>C (21). Genotyping of apoA-V 1131C was linked to lower LDL levels, and SW19 polymorphisms were linked to higher TG levels in patients with T2DM (Table II) (22). However, another study reported that the apoA-V 1131T>C SNP does not affect LDL levels in healthy people (23).

\section{Relationship between apoB and T2DM}

Introduction to apoB. ApoB is a component of CMs, very low-density lipoprotein (VLDL), intermediate-density lipoprotein and LDL (24). ApoB48 is $48 \%$ of the full-length protein; however, VLDL contains only full-length apoB in humans. In T2DM, the increased flux of free fatty acids promotes hepatic TG production, which subsequently induces apoB and VLDL secretion (2). TGs transported by VLDL are exchanged for HDL-transported cholesteryl esters through the action of cholesteryl ester transfer protein (CETP) (2). As a result of this exchange, the concentration of both atherogenic cholesterol-rich VLDL remnant particles and TG-rich, cholesterol-depleted HDL particles are increased. In addition, TG transfer from VLDL to LDL may be through CETP, in exchange for LDL-transported cholesteryl ester (2). TG-rich LDL may be hydrolysed by hepatic lipases or LPLs, which may result in lipid-depleted sd-LDL (Fig. 1) (2). Then, Forkhead box (Fox) O1 becomes inhibited, leading to increased expression of microsomal triglyceride transfer protein and apoC-III. Meanwhile, the multicomponent mechanistic target of rapamycin complex 1 remains activated, suppressing sortilin, which can decrease apoB and triglyceride secretion; subsequently, the ability of insulin to suppress apoB secretion is diminished and, thus, apoB secretion is increased (24).

Metabolism of apoB in T2DM and its complications. ApoB clearance is decreased and the levels of plasma apoB are increased in patients with T2DM (Fig. 1; Table I) (12). CETP protein expression level and activity, and HDL levels are significantly increased, whereas apoB levels are significantly decreased following insulin treatment (25). These results suggested that insulin may reduce apoB concentrations and serve an antiatherosclerotic role. Dyslipidaemia (higher TG and VLDL), abnormal gene expression (glucose transporters 1 and 2, and glycogen synthase kinase 3), abnormal protein expression (tumor necrosis factor-a, interleukin-6, retinol binding protein 4 and soluble cluster of differentiation 36), and phosphorylation of multiple pathways components (insulin receptor substrate 2/Akt protein/protein tyrosine phosphatase-1B) related to inflammatory insulin signalling may be associated with VLDL-apoB100 particle overproduction in T2DM (26). Increased levels of circulating glycated apoB in T2DM are probably linked with greater susceptibility of sd-LDL to glycation (4). The apoB/apoA-I ratio was 


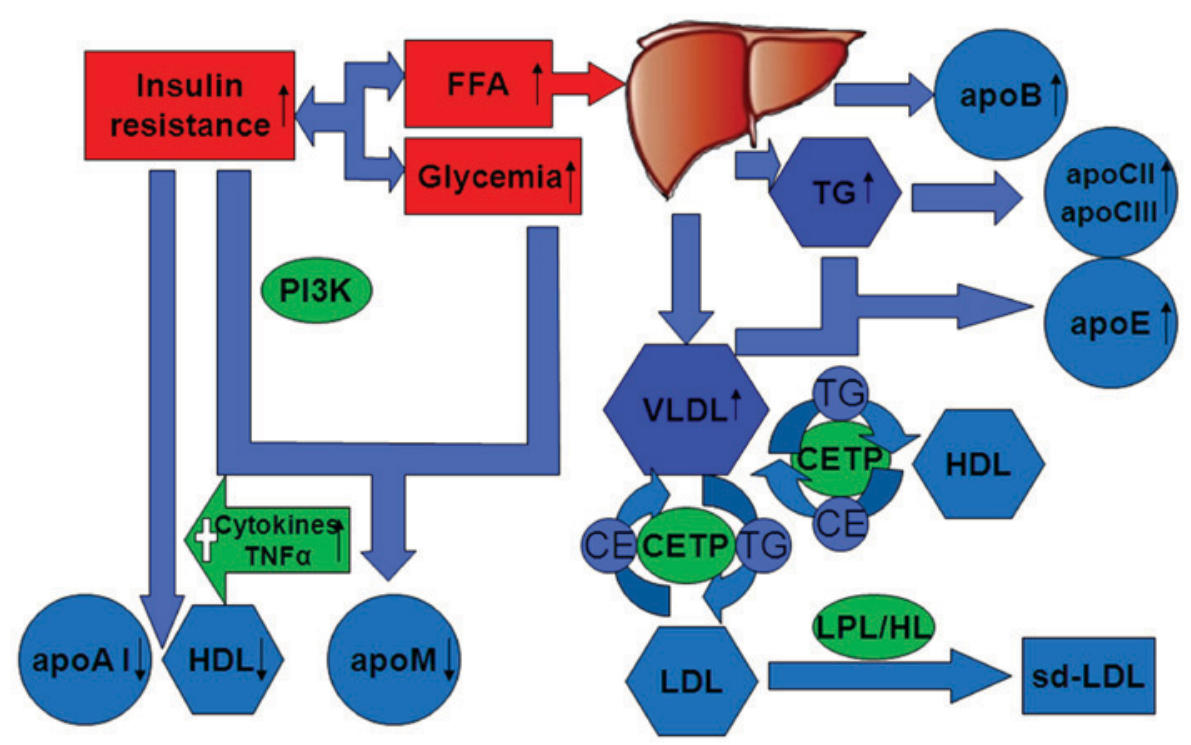

Figure 1. Altered expression of apolipoproteins and lipoproteins in type 2 diabetes mellitus. Insulin resistance initiates the characteristic of high TG level, low HDL cholesterol level and high sd-LDL level, as well as high levels of apoB, apoC-II, apoC-III and apoE, and low levels of apoA-1 and apoM. When the concentrations of VLDL-transported TG are high, CETP promotes the transfer of LDL CE in exchange for TG. TG-rich LDL can undergo hydrolysis by HL or LPL. The rate of HDL degradation is increased and its production is not altered, resulting in decreased plasma HDL. apo, apolipoprotein; CE, colesteryl ester; CETP, cholesteryl ester transfer protein; FFA, free fatty acid; HDL, high-density lipoprotein; HL, hepatic lipase; LDL, low-density lipoprotein; LPL, lipoprotein lipase; PI3K, phosphatidylinositol 3-kinase; sd-LDL, high small low-density lipoprotein; TG, triglyceride; VLDL, very low-density lipoprotein.

revealed to be independently associated with T2DM (27). Patients with T2DM and albuminuria exhibit greater levels of circulating apoB (28), which indicated that apoB may also be associated with diabetic nephropathy. A strong independent negative correlation between the total fractional catabolic rate of VLDL-apoB100 and plasma RBP4 concentration in T2DM has been reported previously (29), which suggested that RBP4 may reduce VLDL-apoB100 catabolism.

apoB/apoA-I ratio and serum apoB concentration were revealed to be higher in patients with T2DM and CVD compared with those with T2DM without CVD $(3,30)$, which suggested that the apoB/apoA-I ratio may be an indicator of CVD risk in patients with T2DM (Table I). Significant correlations have also been made between apoB48 and carotid intima-media thickness (31), which indicated that fasting apoB48 levels may aid in predicting arterial stiffness in middle-aged patients with T2DM. Plasma apoB48 concentration may also be an independent predictor of vasodilator function in the brachial artery (32), and fasting apoB48 may be an independent marker of peripheral arterial disease in patients with T2DM (33). Data from these previous studies indicated that plasma apoB concentrations may be associated with cardiovascular events in T2DM patients.

\section{Relationship between apoC and T2DM}

Introduction to apoC. ApoC comprises apoC-I, apoC-II and apoC-III, which are mainly components of CMs, VLDL and HDL, and participates in the metabolism of these lipoprotein particles (34). ApoC-I is a potent activator of lecithin-cholesterol acyltransferase (LCAT), and excess LCAT results in increased total cholesterol (TC) and TG levels (34). At intermediate concentrations and in normolipidaemic individuals, apoC-II activates LPL. However, both very high and very low concentrations of apoC-II have been associated with decreased LPL activity and hypertriglyceridaemia (34). Overproduction of apoC-II was associated with increased TG-rich particles and alterations in the distribution of HDL particle, both of which are factors that may increase the risk of CVD (34).

Metabolism of apoC in T2DM and its complications. Plasma concentration levels of both apoC-II and apoC-III, as well as the apoC-II/apoC-III ratio, were reported to be markedly higher in patients with T2DM, and this increase was associated with elevated TG (Fig. 1; Table I) (34). Glucose induces apoC-III transcription, which may represent a mechanism that links hyperglycaemia, hypertriglyceridaemia and CVD in patients with T2DM; this process is inhibited by treatment with agonists of farnesoid $\mathrm{X}$ receptor and peroxisome proliferator-activated receptor- $\alpha$ (35). The highest tertile of HDL apoC-III was reported to be a major independent predictor of new-onset T2DM in the Turkish population, particularly in women in which the middle tertile was also indicated to be highly predictive of T2DM; however, non-HDL apoC-III does not independently predict T2DM (36). Plasma apoC-III levels may be altered in individuals with a family history of diabetes (34), indicating that the latter is an important factor for apoC-III.

ApoC-III delays TG-rich lipoprotein lipolysis by inhibiting the expression of LPL and the hepatic uptake of TG-rich lipoproteins by remnant receptors, and is strongly associated with hypertriglyceridaemia and CVD progression (37). apoC-III plasma concentration may strongly and independently predict coronary events in T2DM (37). In patients with T2DM, high levels of apoC-III increase the susceptibility of LDL to hydrolysis and aggregation by sphingomyelinases (38). The sialylation of apoC-III, which increases with increased 
Table I. Altered plasma concentrations of apolipoproteins in T2DM and its complications.

\begin{tabular}{|c|c|c|c|}
\hline Apo & T2DM vs. healthy & $\begin{array}{l}\text { T2DM with } \\
\text { CVD vs. T2DM }\end{array}$ & T2DM with other diseases \\
\hline \multirow[t]{4}{*}{ apoA } & apoA-I $\downarrow(3,50)$ & apoA-I $\downarrow$ (3) & $\begin{array}{l}\text { 1. T2DM with MetS vs. only MetS:apoA-I } \downarrow \text {; } \\
\text { apoA-I:apoB } \downarrow \text { (17) }\end{array}$ \\
\hline & Glycated apoA-I $\uparrow(3)$ & Glycated apoA-I $\uparrow(3)$ & $\begin{array}{l}\text { 2. T2DM on haemodialysis vs. healthy } \\
\text { people:apoA-IV } \downarrow \text { (13) }\end{array}$ \\
\hline & & & 3. PDR vs. NPDR:apoA-I $\downarrow$; apoA-I:B $\downarrow$ (14) \\
\hline & & & $\begin{array}{l}\text { 4. T2DM with MOP vs. MOP:apoA-IV } \uparrow \text { in } \\
\text { jejunum (15) }\end{array}$ \\
\hline \multirow[t]{2}{*}{ apoB } & apoB $\uparrow(3,50)$ & apoB $\uparrow(3)$ & $\begin{array}{l}\text { 1. T2DM with MOP vs. only MOP:apoB } 48 \uparrow \\
\text { in jejunum (15) }\end{array}$ \\
\hline & Glycated apoB $\uparrow(15)$ & apoB:A-I $\uparrow(30)$ & $\begin{array}{l}\text { 2. Albuminuric T2DM vs. normoalbuminuric } \\
\text { T2DM:apoB } \uparrow(28)\end{array}$ \\
\hline
\end{tabular}

$\begin{array}{llll}\text { apoC } & \text { apoC-II } \uparrow ; \text { apoC-III } \uparrow & \text { LDL-apoC-III } \uparrow(38) & \begin{array}{l}\text { 1. T2DM with MetS vs. only MetS:apoC-II } \\ \text { unchanged (17) }\end{array} \\ \text { apoD } & \begin{array}{l}\text { apoC-III:C-II } \downarrow \text { (34) } \\ \text { no research }\end{array} & \begin{array}{l}\text { apoC-II } \uparrow(39) \\ \text { no research }\end{array} & \text { No research } \\ \text { apoE } & \text { apoE } \uparrow(50) & & \text { 1. T2DM with hyperlipidaemia vs. only } \\ \text { apoM } & \text { apoM } \downarrow(63) & & \text { T2DM:apoM unchanged (59) }\end{array}$

$\downarrow$, decrease; $\uparrow$, increase; apo, apolipoprotein; CVD, cardiovascular disease; MetS, metabolic syndrome; MOP, morbidly obese person; NPDR, non-proliferative diabetic retinopathy; PDR, proliferative diabetic retinopathy; T2DM, type 2 diabetes mellitus.

apoC-III concentration, are essential for its pro-inflammatory properties, could increase CVD risk (38). Chronic underexpression of apoC-III may also affect heart functions (39). apoC-II levels are higher in patients with T2DM and CVD compared with patients without CVD (39). These results indicated that apoC-II and apoC-III serve important roles in cardiac events.

Gene mutations and polymorphisms of apoC in T2DM. Circulating apoC-III is an independent determinant of both incident T2DM and CVD. T2DM patients with apoC-III 482TT homozygotes have higher apoC-III levels compared with C-allele carriers (40). In lean patients, the apoC-III 482TT allele was associated with an increased risk of T2DM, but no association was made in overweight patients. Lean patient carriers of the $482 \mathrm{C}>\mathrm{T}$ allele may require more frequent insulin therapy, which may be an effect of apoC-III variants on $\beta$-cell function. This genetic overlap also occurs in T1DM (41). ApoC-III 1,100C $>$ T was reported to be associated with an increased risk of T2DM and this effect was independent of the effects on TG levels (42). A previous study investigated genetic variations in the 3 'flanking region of apoA-I (Pst I), the 3'untranslated region of apoC-III (SstI) and intron 2 of apoA-IV $(X b a \mathrm{I})$ in 435 patients with T2DM and revealed that the P1-S2-X1 haplotype increased the risk of CVD in patients with T2DM (Table II) (39). Patients with T2DM and the apoC-III m482 AA polymorphism exhibited lower cognitive functions and significantly higher glucose and TC levels compared with patients with the AG or GG genotypes. Patients with T2DM and the apoC-III $3 \mathrm{u} 386 \mathrm{GC}$ or GG polymorphism exhibited significantly higher TG, TC and glucose levels compared with Caribbean Hispanic patients with the CC genotype (43).

\section{Relationship between apoD and T2DM}

ApoD is expressed in numerous tissues, including brain, intestine, liver, cardiac and skeletal muscle, adipose tissue and pancreas. In plasma, apoD is mainly bound to HDL, with a low level of apoD bound to VLDL and LDL, which suggested that apoD may serve an important role in the metabolism of both TG and TC (44). ApoD is a potent activator of LCAT. apoA-I and apoC-I can also modulate LCAT activity by stabilizing the enzyme on HDL (44), indicating that apoD may have some interaction with apoA-I and apoC-I in HDL metabolization, although further studies are required. ApoD also serves a role in HDL remodelling through covalent crosslinking with apoA-II, a structural component of HDL (44). Previous studies investigating the association between apoD and T2DM are limited; however, it has been reported that apoD serves an important role in oxidative stress, which is closely associated with insulin resistance and diabetes (45). Another study demonstrated that apoD functions to protect against lipid peroxidation and oxidative stress (46). ApoD expression was also revealed to be upregulated in cultured myotubes from patients with T2DM (46). A linkage has been observed between the TaqI polymorphism of apoD and T2DM in South Indians, Nauruans and British Caucasian populations (Table II) $(47,48)$. T2DM may influence the expression levels of apoD mRNA in the hypothalamus of obese $\mathrm{db} / \mathrm{db}$ mice (46); 
Table II. Polymorphisms of apolipoproteins with the susceptibility of T2DM.

\begin{tabular}{|c|c|}
\hline apo & Apolipoprotein polymorphism \\
\hline apoA & $\begin{array}{l}\text { apoA-V } 1131 \mathrm{~T}>\mathrm{C} \text { polymorphisms influence plasma TG levels and LDL levels in T2DM (19); other studies } \\
\text { do not find the association }(21,23)\end{array}$ \\
\hline apoB & No research \\
\hline apoC & $\begin{array}{l}\text { 1. apoC-III } 482 \mathrm{~T} \text { allele is associated with increased risk of T2DM (41) } \\
\text { 2. apoC-III } 1100 \mathrm{C}>\mathrm{T} \text { is associated with increased risk of T2DM in Caucasian Europeans (42) } \\
\text { 3. apoC-III P1-S2-X1 is a susceptibility haplotype that increases the risk of coronary heart disease in } \\
\text { T2DM (39) }\end{array}$ \\
\hline apoD & $\begin{array}{l}\text { apoD TaqI polymorphism is associated with susceptibility of T2DM in South Indians, Nauruans and British } \\
\text { Caucasians }(47,48)\end{array}$ \\
\hline apoE & $\begin{array}{l}\text { 1. apoE } \varepsilon 4 \text { allele is associated with increased risk of T2DM (57) and severe neuropathy, ischemic heart } \\
\text { disease (55), coronary artery disease (56) and Alzheimer disease in T2DM (59) } \\
\text { 2. apoE } \varepsilon 4 \text { allele is associated with increased risk of cardiovascular events in patients with T2DM and } \\
\text { end-stage renal disease (58) }\end{array}$ \\
\hline & $\begin{array}{l}\text { 3. apoE } \varepsilon 2 \text { allele is associated with increased risk of T2DM ( } 51) \\
\text { 4. apoE } \varepsilon 2 / 3 \text { genotype increase the risk for diabetic nephropathy (53) }\end{array}$ \\
\hline apoM & $\begin{array}{l}\text { 1. apoM T-778C is associated with increased risk of T2DM ( } 69) \\
\text { 2. apoM C-1065 allele is associated with T2DM duration of }>10 \text { years ( } 71) \\
\text { 3. apoM C-724del is associated with T2DM (67) }\end{array}$ \\
\hline
\end{tabular}

Apo, apolipoprotein; LDL, low-density lipoprotein; T2DM, type 2 diabetes mellitus; TG, triglycerides.

however, the underlying pathophysiological role of apoD in $\mathrm{T} 2 \mathrm{DM}$ is not clear. Therefore, further research is required.

\section{Relationship between apoE and T2DM}

Introduction to apoE. ApoE possesses three major alleles ( $22, \varepsilon 3$ and $\varepsilon 4)$ and encodes a 299 amino-acids-long protein that has three isoforms (E2, E3 and E4). $\varepsilon 3$ is the most common isoform and has a frequency of $70-80 \%$; whereas the frequency of $\varepsilon 2$ and $\varepsilon 3$ are 5-10 and 10-15\%, respectively (49). ApoE is a component of VLDL, CMs and HDL; increased production and secretion of apoE by the liver, or accumulation of apoE in the plasma has been associated with increased VLDL synthesis and secretion (50). ApoE serves an important role in regulating plasma and cellular lipid concentrations (50).

Metabolism of apoE in T2DM. As insulin resistance is associated with metabolic dyslipidaemia, the function of apoE isoforms in lipid metabolism may serve an important role in T2DM pathogenesis (51). Serum apoE concentrations were previously demonstrated to be elevated in patients with T2DM (Fig. 1; Table I) (52). The serum levels of apoE are independently associated with urinary albumin excretion in patients with T2DM, and levels are significantly higher in patients with albuminuria and T2DM compared with T2DM alone (51), which indicated that apoE may be related to T2DM and its complications.

Association between apoE genotype and T2DM. A meta-regression analysis suggested that carriers of the apoE $\varepsilon 2$ allele have an increased risk for T2DM, and the apoE $\varepsilon 2 / 3$ genotype may increase the risk of diabetic nephropathy (53). The apoE $\varepsilon 4$ allele is has been associated with the development of T2DM and severe peripheral neuropathy in patients with T2DM (54). In addition, the $\varepsilon 4$ allele may be linked with the development of ischemic heart disease in patients with T2DM (55). ApoE $\varepsilon 4$ has also been associated with the development of T2DM with CAD (Table II) $(56,57)$, as well as increased risk of cardiovascular events and related mortalities in patients with T2DM and end-stage renal disease (Table I) (58). A number of previous human and animal studies have reported a causal link between aberrant insulin metabolism, both hypoinsulinaemia and insulin resistance, and the pathogenesis of Alzheimer's disease (AD) (49). T2DM and prediabetic states, such as abnormal glucose tolerance and insulin resistance, have been implicated as risk factors of AD. Compared with those who have neither T2DM nor the apoE $\varepsilon 4$ allele, patients with both factors have a higher risk of developing AD, mixed AD (59) and cognitive dysfunction (60), which suggested that apoE may be a risk factor of AD. A strong association has been made between T2DM and the development of $\mathrm{AD}$ in patients with T2DM and the apoE $\varepsilon 4$ allele that also have numerous neuritic plaques and neurofibrillary tangles in the cortex and hippocampus, and with a high burden of cerebral amyloid angiopathy (61). In addition, protein and mRNA expressions of insulin-degrading enzyme are significantly reduced in the hippocampus in patients with $\mathrm{AD}$ that carry the apoE $\varepsilon 4$ genotype (49). These data suggested that carrying the apoE $\varepsilon 4$ allele may increase the risk of developing AD in patients with T2DM (Table I).

\section{Relationship between apoM and T2DM}

Introduction to apoM. ApoM expression is highly tissue specific; it is mainly expressed in liver and kidney, and weakly 
expressed in embryonic liver and kidney, stomach, muscle cells, heart, intestine, brain, spleen and testes; however, expression has not been detected in muscle tissue, duodenum and ovaries (62). ApoM is present in HDL and, to a lower degree, in TG-rich lipoproteins and LDL in plasma. ApoM is crucial for pre-b-HDL formation and cholesterol efflux to HDL; it protects against atherosclerosis (63). Previous studies have indicated that apoM may be associated with both apoA-I and apoE $(64,65)$. For example, ApoM may be an independent predictor of apoA-I and apoA-II catabolism in overweight/obese, insulin-resistant men (64). ApoM expression is reduced in diabetic mice and its synthesis may be regulated by insulin (62). Furthermore, phosphatidylinositol 3-kinase may also control the expression of apoM in HepG2 human liver carcinoma cells. apoM may serve a role in the metabolism of glucose and lipids by regulating peroxisome proliferator-activated receptor $\gamma(66)$.

Metabolism of apoM in T2DM. Plasma concentrations of apoM are $9 \%$ lower in patients with T2DM compared with healthy control individuals in Caucasians (Fig. 1; Table I) (67). Our recent research also demonstrated that Chinese T2DM patients also had lower apoM levels than healthy controls (68). Of note, no differences of plasma apoM concentrations were observed between T2DM patients and healthy controls, indicating that low plasma apoM in T2DM may be the accompanying effect of HDL (68).

Gene mutations and polymorphisms of apoM in T2DM. The apoM T-778C SNP was notably associated with T2DM in the Han Chinese population (69). Plasma TC levels were demonstrated to be significantly higher in individuals with apoM T-778C CC or CT genotype compared with TT genotype in healthy people (70). However, the apoM T-778C TT genotype was significantly associated with elevated plasma TC and LDL levels in patients with T2DM (67). In vitro experiment demonstrated that apoM T-778C T allele could led to ectopic expression of apoM transcript, which can modify hepatic cell cholesterol content (67). In addition, the allele $\mathrm{C}$ of the apoM C-1065A SNP was significantly increased in patients with T2DM $>10$ years compared with those in T2DM duration $<10$ years (Table II) (71). A recent study reported that the apoM C-724del SNP was associated with CVD and myocardial infarction (72), and another study demonstrated that this polymorphism was also related to T2DM (67).

\section{Conclusions and prospects}

Dyslipidaemia in patients with T2DM is characterised by high plasma TG, reduced HDL and increased sd-LDL. Dyslipidaemia may lead to atherosclerosis and other complications, and is closely associated with insulin resistance (Fig. 1) (2). Complex metabolic disorders of apolipoproteins in T2DM occur, such as high plasma concentrations of apoB, apoC-II, apoC-III and apoE, and low plasma concentrations of apoA-I and apoM, which are associated with dyslipidaemia and the pathophysiology of complications (Fig. 1; Table I) $(3,34,50,63)$. T2DM combined with CVD and other complications also affect plasma apolipoprotein concentrations (Table I) $(3,38,39)$. Certain apolipoprotein polymorphisms are related to the susceptibility of T2DM, as well as complications and lipid metabolism $(19,21,23,39,41,42$, 47,48,51,53,55-59,66,68,70); however, the complex mechanisms have not been fully elucidated (Table II). In addition, few studies have been conducted on the interactions between each apolipoprotein. Apolipoproteins are closely related to diabetes and other metabolic diseases; however, the complex mechanisms of insulin and glucose regulation of apolipoproteins are not well understood. Thus, the association between apolipoproteins and the pathogenesis of diabetes requires further research.

\section{Acknowledgements}

The authors would like to acknowledge the support of The Anhui Province Key Laboratory of Biological Macro-molecules Research (Wannan Medical College). This study was supported by grants from The Science and technology project in Wuhu (grant no. 2013cxy04), The Anhui Provincial Natural Science Foundation (grant no. 1508085MH149), The Natural Science Research Project of Anhui Colleges and Universities (grant no. KJ2016A737) and The National Natural Science Foundation of China (grant no. 81200632).

\section{References}

1. Ingelfinger JR and Rosen CJ: Cardiac and renovascular complications in type 2 diabetes-is there hope? N Engl J Med 375: 380-382, 2016.

2. Shulman GI: Ectopic fat in insulin resistance, dyslipidemia, and cardiometabolic disease. N Engl J Med 371: 1131-1141, 2014.

3. Nobécourt E, Tabet F, Lambert G, Puranik R, Bao S, Yan L, Davies MJ, Brown BE, Jenkins AJ, Dusting GJ, et al: Nonenzymatic glycation impairs the anti-inflammatory properties of apolipoprotein A-I. Arterioscler Thromb Vasc Biol 30: 766-772, 2010.

4. Younis NN, Soran H, Pemberton P, Charlton-Menys V, Elseweidy MM and Durrington PN: Small dense LDL is more susceptible to glycation than more buoyant LDL in Type 2 diabetes. Clin Sci (Lond) 124: 343-349, 2013.

5. Viney NJ, van Capelleveen JC, Geary RS, Xia S, Tami JA, Yu RZ, Marcovina SM, Hughes SG, Graham MJ, Crooke RM, et al: Antisense oligonucleotides targeting apolipoprotein(a) in people with raised lipoprotein(a): Two randomised, double-blind, placebo-controlled, dose-ranging trials. Lancet 388: 2239-2253, 2016.

6. Rye KA, Barter PJ and Cochran BJ: Apolipoprotein A-I interactions with insulin secretion and production. Curr Opin Lipidol 27: 8-13, 2016.

7. Lehti M, Donelan E, Abplanalp W, Al-Massadi O, Habegger KM, Weber J, Ress C, Mansfeld J, Somvanshi S, Trivedi C, et al: High-density lipoprotein maintains skeletal muscle function by modulating cellular respiration in mice. Circulation 128: 2364-2371, 2013.

8. Fryirs MA, Barter PJ, Appavoo M, Tuch BE, Tabet F, Heather AK and Rye KA: Effects of high-density lipoproteins on pancreatic beta-cell insulin secretion. Arterioscler Thromb Vasc Biol 30: 1642-1648, 2010.

9. Duvillard L, Dautin G, Florentin E, Jeannin A, Pais de Barros JP, Lagrost L, Petit JM, Gambert P and Vergès B: Increased apolipoprotein AI production rate and redistribution of high-density lipoprotein size induced by estrogen plus progestin as oral contraceptive. J Clin Endocrinol Metab 94: 4891-4897, 2009.

10. Bisoendial R, Tabet F, Tak PP, Petrides F, Cuesta Torres LF, Hou L, Cook A, Barter PJ, Weninger W and Rye KA: Apolipoprotein A-I limits the negative effect of tumor necrosis factor on lymphangiogenesis. Arterioscler Thromb Vasc Biol 35: 2443-2450, 2015.

11. Tabet F, Lambert G, Cuesta Torres LF, Hou L, Sotirchos I, Touyz RM, Jenkins AJ, Barter PJ and Rye KA: Lipid-free apolipoprotein A-I and discoidal reconstituted high-density lipoproteins differentially inhibit glucose-induced oxidative stress in human macrophages. Arterioscler Thromb Vasc Biol 31: 1192-1200, 2011 
12. Pu LJ, Lu L, Zhang RY, Du R, Shen Y, Zhang Q, Yang ZK, Chen QJ and Shen WF: Glycation of apoprotein A-I is associated with coronary artery plaque progression in type 2 diabetic patients. Diabetes Care 36: 1312-1320, 2013.

13. Kollerits B, Krane V, Drechsler C, Lamina C, März W, Ritz E, Wanner C and Kronenberg F; German Diabetes and Dialysis Study Investigators: Apolipoprotein A-IV concentrations and clinical outcomes in haemodialysis patients with type 2 diabetes mellitus-a post hoc analysis of the 4D Study. J Intern Med 272 592-600, 2012

14. Hu A, Luo Y, Li T, Guo X, Ding X, Zhu X, Wang X and Tang S: Low serum apolipoprotein A1/B ratio is associated with proliferative diabetic retinopathy in type 2 diabetes. Graefes Arch Clin Exp Ophthalmol 250: 957-962, 2012.

15. Soriguer F, Garcia-Serrano S, Garrido-Sánchez L, Gutierrez-Repiso C, Rojo-Martínez G, Garcia-Escobar E, García-Arnés J, Gallego-Perales JL, Delgado V and García-Fuentes E: Jejunal wall triglyceride concentration of morbidly obese persons is lower in those with type 2 diabetes mellitus. J Lipid Res 51: 3516-3523, 2010

16. Galazis N, Afxentiou T, Xenophontos M, Diamanti-Kandarakis E and Atiomo W: Proteomic biomarkers of type 2 diabetes mellitus risk in women with polycystic ovary syndrome. Eur J Endocrinol 168: R33-R43, 2013

17. Wang W, Khan S, Blackett $P$, Alaupovic $P$ and Lee E: Apolipoproteins A-I, B, and C-III in young adult Cherokee with metabolic syndrome with or without type 2 diabetes. J Clin Lipidol 7: 38-42, 2013.

18. Mendes-Lana A, Pena GG, Freitas SN, Lima AA, Nicolato RL, Nascimento-Neto RM, Machado-Coelho GL and Freitas RN: Apolipoprotein E polymorphism in Brazilian dyslipidemic individuals: Ouro Preto study. Braz J Med Biol Res 40: 49-56, 2007.

19. Charriere S, Bernard S, Aqallal M, Merlin M, Billon S, Perrot L, Le Coquil E, Sassolas A, Moulin P and Marcais C: Association of APOA5-1131T >C and S19W gene polymorphisms with both mild hypertriglyceridemia and hyperchylomicronemia in type 2 diabetic patients. Clin Chim Acta 394: 99-103, 2008.

20. Cabré A, Lázaro I, Girona J, Manzanares JM, Marimón F, Plana N, Guardiola M, Heras M and Masana L: The APOA5-1131 $\mathrm{T}>\mathrm{C}$ variant enhances the association between RBP4 and hypertriglyceridemia in diabetes. Nutr Metab Cardiovasc Dis 20 243-248, 2010.

21. Celap I, Simundic AM, Nikolac N, Kackov S and Katalinic D: Association of APOA5-1131T $>C$ polymorphism and serum lipid levels in patients with type 2 diabetes. DNA Cell Biol 32: 589-593, 2013

22. Sóter MO, Gomes KB, Fernandes AP, Carvalho Md, Pinheiro PS, Bosco AA, Silva DD and Sousa MO: -1131T>C and SW19 polymorphisms in APOA5 gene and lipid levels in type 2 diabetic patients. Mol Biol Rep 39: 7541-7548, 2012.

23. Brito DD, Fernandes AP, Gomes KB, Coelho FF, Cruz NG, Sabino AP, Cardoso JE, Figueiredo-Filho PP, Diamante R, Norton CR and Sousa MO: Apolipoprotein A5-1131T $>$ C polymorphism, but not APOE genotypes, increases susceptibility for dyslipidemia in children and adolescents. Mol Biol Rep 38 4381-4388, 2011

24. Sørensen LP, Andersen IR, Søndergaard E, Gormsen LC, Schmitz O, Christiansen JS and Nielsen S: Basal and insulin mediated VLDL-triglyceride kinetics in type 2 diabetic men. Diabetes 60: 88-96, 2011

25. Aslan I, Kucuksayan E and Aslan M: Effect of insulin analog initiation therapy on LDL/HDL subfraction profile and HDL associated enzymes in type 2 diabetic patients. Lipids Health Dis 12: 54, 2013.

26. Qin B, Anderson RA, Kuzuya T, Kitaura Y and Shimomura Y Multiple factors and pathways involved in hepatic very low density lipoprotein-apoB100 overproduction in Otsuka Long-Evans Tokushima Fatty rats. Atherosclerosis 222 : 409-416, 2012

27. Hwang YC, Ahn HY, Kim WJ, Park CY and Park SW: Increased apoB/A-I ratio independently associated with Type 2 diabetes mellitus: Cross-sectional study in a Korean population. Diabet Med 29: 1165-1170, 2012

28. Pan J, Gao F, Bao Y, Zhang L, Tu Y and Jia W: Non-high-density lipoprotein cholesterol is associated more closely with albuminuria in Chinese type 2 diabetic patients with normal renal function, compared with traditional lipid parameters. J Clin Lipidol 6: 382-387, 2012.
29. Vergès B, Guiu B, Cercueil JP, Duvillard L, Robin I, Buffier P, Bouillet B, Aho S, Brindisi MC and Petit JM: Retinol-binding protein 4 is an independent factor associated with triglycerides and a determinant of very low-density lipoprotein-apolipoprotein B100 catabolism in type 2 diabetes mellitus. Arterioscler Thromb Vasc Biol 32: 3050-3057, 2012.

30. Taskinen MR, Barter PJ, Ehnholm C, Sullivan DR, Mann K, Simes J, Best JD, Hamwood S and Keech AC; FIELD study investigators: Ability of traditional lipid ratios and apolipoprotein ratios to predict cardiovascular risk in people with type 2 diabetes. Diabetologia 53: 1846-1855, 2010.

31. Dahlén EM, Bjarnegard N, Länne T, Nystrom FH and Ostgren CJ: Sagittal abdominal diameter is a more independent measure compared with waist circumference to predict arterial stiffness in subjects with type 2 diabetes-a prospective observational cohort study. Cardiovasc Diabetol 12: 55, 2013

32. Chan DC, Wong AT, Yamashita S and Watts GF: Apolipoprotein B-48 as a determinant of endothelial function in obese subjects with type 2 diabetes mellitus: Effect of fenofibrate treatment. Atherosclerosis 221: 484-489, 2012.

33. Mancera-Romero J, Sánchez-Chaparro MA, Rioja J, Ariza MJ, Olivecrona G, González-Santos P and Valdivielso P: Fasting apolipoprotein B48 is a marker for peripheral arterial disease in type 2 diabetes. Acta Diabetol 50: 383-389, 2013.

34. Béliard S, Nogueira JP, Maraninchi M, Lairon D, Nicolay A, Giral P, Portugal H, Vialettes B and Valéro R: Parallel increase of plasma apoproteins C-II and C-III in Type 2 diabetic patients. Diabet Med 26: 736-739, 2009.

35. Caron S, Verrijken A, Mertens I, Samanez CH, Mautino G, Haas JT, Duran-Sandoval D, Prawitt J, Francque S, Vallez E, et al: Transcriptional activation of apolipoprotein CIII expression by glucose may contribute to diabetic dyslipidemia. Arterioscler Thromb Vasc Biol 31: 513-519, 2011.

36. Onat A, Hergenc G, Ayhan E, Uğur M, Kaya H, Tuncer M and Can G: Serum apolipoprotein C-III in high-density lipoprotein: A key diabetogenic risk factor in Turks. Diabet Med 26: 981-988, 2009.

37. Lee SJ, Campos H, Moye LA and Sacks FM: LDL containing apolipoprotein CIII is an independent risk factor for coronary events in diabetic patients. Arterioscler Thromb Vasc Biol 23: 853-858, 2003.

38. Hiukka A, Stahlman M, Pettersson C, Levin M, Adiels M, Teneberg S, Leinonen ES, Hultén LM, Wiklund O, Oresic M, et al: ApoCIII-enriched LDL in type 2 diabetes displays altered lipid composition, increased susceptibility for sphingomyelinase, and increased binding to biglycan. Diabetes 58: 2018-2026, 2009.

39. Singh P, Singh M, Gaur S and Kaur T: The ApoAI-CIII-AIV gene cluster and its relation to lipid levels in type 2 diabetes mellitus and coronary heart disease: Determination of a novel susceptible haplotype. Diab Vasc Dis Res 4: 124-129, 2007.

40. Onat A, Erginel-Unaltuna N, Coban N, Cicek G and Yüksel H: APOC 3-482C $>$ T polymorphism, circulating apolipoprotein C-III and smoking: Interrelation and roles in predicting type-2 diabetes and coronary disease. Clin Biochem 44: 391-396, 2011.

41. van Hoek M, van Herpt TW, Dehghan A, Hofman A, Lieverse AG, van Duijn CM, Witteman JC and Sijbrands EJ: Association of an APOC3 promoter variant with type 2 diabetes risk and need for insulin treatment in lean persons. Diabetologia 54: 1360-1367, 2011.

42. Dorfmeister B, Cooper JA, Stephens JW, Ireland H, Hurel SJ, Humphries SE and Talmud PJ: The effect of APOA5 and APOC3 variants on lipid parameters in European Whites, Indian Asians and Afro-Caribbeans with type 2 diabetes. Biochim Biophys Acta 1772: 355-363, 2007.

43. Smith CE, Tucker KL, Scott TM, Van Rompay M, Mattei J, Lai CQ, Parnell LD, Junyent M, Lee YC, Garcia-Bailo B and Ordovás JM: Apolipoprotein C3 polymorphisms, cognitive function and diabetes in Caribbean origin Hispanics. PLoS One 4: e5465, 2009

44. Lim W, Bae H and Song G: Differential expression of apolipoprotein $\mathrm{D}$ in male reproductive system of rats by high-fat diet. Andrology 4: 1115-1122, 2016.

45. Dassati S, Waldner A and Schweigreiter R: Apolipoprotein D takes center stage in the stress response of the aging and degenerative brain. Neurobiol Aging 35: 1632-1642, 2014.

46. Hansen L, Gaster M, Oakeley EJ, Brusgaard K, Damsgaard Nielsen EM, Beck-Nielsen H, Pedersen O and Hemmings BA: Expression profiling of insulin action in human myotubes: Induction of inflammatory and pro-angiogenic pathways in relationship with glycogen synthesis and type 2 diabetes. Biochem Biophys Res Commun 323: 685-695, 2004. 
47. Baker WA, Hitman GA, Hawrami K, McCarthy MI, Riikonen A, Tuomilehto-Wolf E, Nissinen A, Tuomilehto J, Mohan V, Viswanathan M, et al: Apolipoprotein D gene polymorphism: A new genetic marker for type 2 diabetic subjects in Nauru and south India. Diabet Med 11: 947-952, 1994.

48. Vijayaraghavan S, Hitman GA and Kopelman PG: Apolipoprotein-D polymorphism: A genetic marker for obesity and hyperinsulinemia. J Clin Endocrinol Metab 79: 568-570, 1994.

49. Miranda LF, Gomes KB, Tito PA, Silveira JN, Pianetti GA Byrro RM, Peles PR, Pereira FH, Santos TR, Assini AG, et al: Clinical response to donepezil in mild and moderate dementia: Relationship to drug plasma concentration and CYP2D6 and APOE genetic polymorphisms. J Alzheimers Dis 55: 539-549, 2017.

50. Okamoto N, Morikawa M, Amano N, Yanagi M, Takasawa S and Kurumatani N: Effects of tooth loss and the apolipoprotein E $\varepsilon 4$ Allele on mild memory impairment in the Fujiwara-kyo study of Japan: A Nested Case-Control Study. J Alzheimers Dis 55: 575-583, 2017.

51. Anthopoulos PG, Hamodrakas SJ and Bagos PG: Apolipoprotein E polymorphisms and type 2 diabetes: A meta-analysis of 30 studies including 5423 cases and 8197 controls. Mol Genet Metab 100: 283-291, 2010.

52. Tan KC, Shiu SW, Wong Y, Wong WK and Tam S: Plasma apolipoprotein $\mathrm{E}$ concentration is an important determinant of phospholipid transfer protein activity in type 2 diabetes mellitus. Diabetes Metab Res Rev 22: 307-312, 2006.

53. Reis KA, Ebinc FA, Koc E, Demirci H, Erten Y, Güz G, Derici UB, Bali M, Söylemezoğlu O, Arınsoy T and Sindel S: Association of the angiotensinogen M235T and APO E gene polymorphisms in Turkish type 2 diabetic patients with and without nephropathy. Ren Fail 33: 469-474, 2011

54. Monastiriotis C, Papanas N, Trypsianis G, Karanikola K, Veletza S and Maltezos E: The $\varepsilon 4$ allele of the APOE gene is associated with more severe peripheral neuropathy in type 2 diabetic patients. Angiology 64: 451-455, 2013.

55. Al-Majed HT, Qasem JA, Al-Sherifi AK, Al-Attar AA Qasem AA and Abdullah SA: Association between apolipoprotein E-polymorphism and Ischemic heart disease patients with or without type 2 diabetes mellitus: A preliminary study in Kuwait. Arch Iran Med 14: 385-388, 2011.

56. Vaisi-Raygani A, Rahimi Z, Tavilani $\mathrm{H}$ and Pourmotabbed $\mathrm{T}$ : Butyrylcholinesterase $\mathrm{K}$ variant and the APOE- $\varepsilon 4$ allele work in synergy to increase the risk of coronary artery disease especially in diabetic patients. Mol Biol Rep 37: 2083-2091, 2010.

57. Chaudhary R, Likidlilid A, Peerapatdit T, Tresukosol D, Srisuma S, Ratanamaneechat S and Sriratanasathavorn C: Apolipoprotein E gene polymorphism: Effects on plasma lipids and risk of type 2 diabetes and coronary artery disease. Cardiovasc Diabetol 11: 36, 2012.

58. Winkler K, Hoffmann MM, Krane V, März W, Drechsler C and Wanner C: Apolipoprotein E genotype predicts cardiovascular endpoints in dialysis patients with type 2 diabetes mellitus. Atherosclerosis 208: 197-202, 2010.

59. Irie F, Fitzpatrick AL, Lopez OL, Kuller LH, Peila R, Newman AB and Launer LJ: Enhanced risk for Alzheimer disease in persons with type 2 diabetes and APOE epsilon4: The Cardiovascular Health Study Cognition Study. Arch Neurol 65: 89-93, 2008.
60. Dore GA,Elias MF, Robbins MA, Elias PK and Nagy Z: Presence of the APOE epsilon4 allele modifies the relationship between type 2 diabetes and cognitive performance: The Maine-Syracuse Study. Diabetologia 52: 2551-2560, 2009.

61. Kempf SJ, Janik D, Barjaktarovic Z, Braga-Tanaka I III, Tanaka S, Neff F, Saran A, Larsen MR and Tapio S: Chronic low-dose-rate ionising radiation affects the hippocampal phosphoproteome in the ApoE-/-Alzheimer's mouse model. Oncotarget 7: 71817-71832, 2016.

62. Zhang P, Gao J, Pu C, Feng G, Wang L, Huang L, Tao Q and Zhang Y: Effects of hyperlipidaemia on plasma apolipoprotein M levels in patients with type 2 diabetes mellitus: An independent case-control study. Lipids Health Dis 15: 158, 2016.

63. Zhang H, Pluhackova K, Jiang Z and Böckmann RA: Binding Characteristics of Sphingosine-1-Phosphate to ApoM hints to assisted release mechanism via the ApoM Calyx-opening. Sci Rep 6: 30655, 2016.

64. Ooi EM, Watts GF, Chan DC, Nielsen LB, Plomgaard P, Dahlbäck B and Barrett PH: Association of apolipoprotein M with high-density lipoprotein kinetics in overweight-obese men. Atherosclerosis 210: 326-330, 2010.

65. Kurano M, Tsukamoto K, Hara M, Ohkawa R, Ikeda H and Yatomi Y: LDL receptor and ApoE are involved in the clearance of ApoM-associated sphingosine 1-phosphate. J Biol Chem 290: 2477-2488, 2015

66. Qu X, Zhao S, Gao J, Hu M, Dong L and Zhang X: Reduced expression and secretion of apolipoprotein $\mathrm{M}$ in fat-fed, streptozotocin-diabetic rats is partially reversed by an artificial ligand of PPAR $\gamma$. Zhong Nan Da Xue Xue Bao Yi Xue Ban 37: 796-801, 2012 (In Chinese)

67. Zhang PH, Gao JL, Pu C, Feng G, Wang LZ, Huang LZ and Zhang Y: A single-nucleotide polymorphism C-724/del in the proter region of the apolipoprotein $\mathrm{M}$ gene is associated with type 2 diabetes mellitus. Lipids Health Dis 15: 142, 2016.

68. Zhang PH, Gao JL, Pu C, Feng G, Wang L, Huang L and Zhang Y: ApoM/HDL-C and apoM/apoA-I ratios are indicators of diabetic nephropathy in healthy controls and type 2 diabetes mellitus. Clin Chim Acta 466: 31-37, 2017.

69. Niu N, Zhu X, Liu Y, Du T, Wang X, Chen D, Sun B, $\mathrm{Gu} \mathrm{HF}$ and Liu Y: Single nucleotide polymorphisms in the proximal promoter region of apolipoprotein $\mathrm{M}$ gene (apoM) confer the susceptibility to development of type 2 diabetes in Han Chinese. Diabetes Metab Res Rev 23: 21-25, 2007.

70. Zhang Z, Chu G and Yin RX: Apolipoprotein M T-778C polymorphism is associated with serum lipid levels and the risk of coronary artery disease in the Chinese population: A meta-analysis. Lipids Health Dis 12: 135, 2013.

71. Zhou JW, Tsui SK, Ng MC, Geng H, Li SK, So WY, Ma RC, Wang Y, Tao Q, Chen ZY, et al: Apolipoprotein M gene (APOM) polymorphism modifies metabolic and disease traits in type 2 diabetes. PLoS One 6: e17324, 2011.

72. Guo H, Zhao XX, Zhang XJ, Chen W and Zhang J: Functional study of -724I/D polymorphism in apolipoprotein $\mathrm{M}$ (apoM) gene promoter region and its association with myocardial infarction. Med Sci Monit 21: 371-375, 2015. 